\title{
Efficient and Rapid Induction of a Chronic Myelogenous Leukemia-Like Myeloproliferative Disease in Mice Receiving P210 bcr/abl-Transduced Bone Marrow
}

\author{
By Warren S. Pear, J uli P. Miller, Lanwei Xu, J ohn C. Pui, Benny Soffer, Robert C. Quackenbush, \\ Ann Marie Pendergast, Roderick Bronson, J on C. Aster, Martin L. Scott, and David Baltimore
}

\begin{abstract}
Expression of the 210-kD bcr/abl fusion oncoprotein can cause a chronic myelogenous leukemia (CML)-like disease in mice receiving bone marrow cells transduced by bcr/ablencoding retrovinuses. However, previous methods failed to yield this disease at a frequency sufficient enough to allow for its use in the study of CML pathogenesis. To overcome this limitation, we have developed an efficient and reproducible method for inducing a CML-like disease in mice receiving P210 bcr/ abl-transduced bone marrow cells. All mice receiving P210 bcr/ abl-transduced bone marrow cells succumb to a myeloproliferative disease between 3 and 5 weeks after bone marrow transplantation. The myeloproliferative disease recapitulates many of the hallmarks of human CML and is characterized by high white blood cell counts and extensive extramedullary hematopoiesis in the spleen, liver, bone
\end{abstract}

C HRONIC MYELOGENOUS leukemia (CML) is a clonal, biphasic disease that accounts for approximately $20 \%$ of all leukemias. ${ }^{1,2}$ The initial or chronic phase of the disease lasts 3 to 5 years, on average, and is characterized by extremely high peripheral white blood cell (WBC) counts and extramedullary hematopoiesis leading to splenomegaly. These characteristics result from expression of the bcr/abl fusion gene that is the product of the $(9 ; 22)$ chromosomal translocation. Expression of the bcr/abl oncoprotein in a hematopoietic progenitor cell is thought to be rate-limiting in the pathogenesis of chronic-phase CML. Almost all patients are diagnosed during chronic phase and this phase of the disease can be successfully palliated with relatively nontoxic drugs. Chronic-phase CML is followed by a terminal blast phase, during which the patient develops an acute

From the Department of Pathology and Institute for Medicine and Engineering, University of Pennsylvania, Philadelphia, PA; the Department of Internal Medicine (Hematology/Oncology), Pharmacology, and Cancer Biology, Duke University School of Medicine, Durham, NC; the Department of Veterinary Medicine, Tufts University, Boston, MA; the Department of Pathology, Brigham and Women's Hospital, Boston, MA; and the Department of Biology, Massachusetts Institute of Technology, Cambridge, MA.

Supported by National Institutes of Health Grants No. RO1CA61033 (A.M.P.), R29CA66849 (J.C.A.), and RO1CA51462 (D.B.); Special Fellowship and Scholar Awards from the Leukemia Society of America (W.S.P. and A.M.P.); Penn/Hughes Award in Developmental Biology (W.S.P.); Mary L. Smith Charitable Trust (W.S.P.); Four Schools Physician-Scientist Program sponsored by the Lucille P. Markey Charitable Trust (R.C.Q.); and the Whitehead Scholar (A.M.P.).

Address reprint requests to Warren S. Pear, MD, PhD, Department of Pathology and Institute for Medicine and Engineering, Vagelos Research Labs (IAST Bldg), 3340 Smith Walk, Philadelphia, PA 191046383; e-mail:wpear@mail.med.upenn.edu.

The publication costs of this article were defrayed in part by page charge payment. This article must therefore be hereby marked "advertisement" in accordance with 18 U.S.C. section 1734 solely to indicate this fact.

(1) 1998 by The American Society of Hematology.

0006-4971/98/9210-0017\$3.00/0 marrow, and lungs. Use of a retroviral vector coexpressing P210 bcr/abl and green fluorescent protein shows that the vast majority of bcr/ abl-expressing cells are myeloid. Analysis of the proviral integration pattem shows that, in some mice, the myeloproliferative disease is clonal. In multiple mice, the CML-like disease has been transplantable, inducing a similar myeloproliferative syndrome within 1 month of transfer to sublethally irradiated syngeneic recipients. The disease in many of these mice has progressed to the development of acute lymphoma/leukemia resembling blast crisis. These results demonstrate that murine $C M L$ recapitulates important features of human CML. As such, it should be an excellent model for addressing specific issues relating to the pathogenesis and treatment of this disease.

(C) 1998 by The American Society of Hematology.

leukemia. In contrast to chronic-phase CML, the blast phase is refractory to treatment and median survival is 2 to 4 months. The only cure for CML is a bone marrow transplant performed during chronic phase.

Identification of the consistent $(9 ; 22)$ translocation has led to a relatively detailed understanding of some of the molecular events in CML. ${ }^{3}$ The molecular consequence of the $t(9 ; 22)$ is juxtaposition of the bcr and abl genes with the consequent expression of an abnormal fusion protein created by the joining of the amino terminus of the bcr protein with the carboxylterminus of the abl protein. ${ }^{4}$ Creation of the P210 bcr/abl fusion protein via chromosomal translocation juxtaposes several protein domains that are thought to contribute to the transforming ability of the fusion protein. Bcr contributes an oligomerization domain, serine-threonine kinase domain, grb2 binding site, $\mathrm{Db} 1$ homology domain, and $\mathrm{PH}$ domain. ${ }^{5-9}$ Important abl protein domains that are retained in the bcr/abl fusion protein include an SH3 domain, which may negatively regulate transformation, an $\mathrm{SH} 2$ domain that binds phosphotyrosine, an SH1 or tyrosine kinase domain, whose presence is absolutely essential for transformation, and sequences for nuclear localization, actin binding, and DNA binding. ${ }^{5,9-12}$ Approximately $92 \%$ of patients with CML express the $210-\mathrm{kD}$ bcr/abl fusion protein, whereas $3 \%$ express the shorter $190-\mathrm{kD}$ fusion protein. The $190-\mathrm{kD}$ bcr/abl fusion protein lacks the Dbl-homology and PH domains that are present in the $\mathrm{P} 210 \mathrm{kD}$ bcr/abl fusion protein.

There are several important differences between the bcr/abl fusion protein and its normal cellular counterparts (c-abl, c-bcr) that may explain the transforming ability of bcr/abl. The abl tyrosine kinase activity of the bcr/abl fusion protein is much greater than that of c-abl. ${ }^{13}$ Unlike c-abl, which is primarily localized in the nucleus in transfected cells, bcr/abl is localized in the cytoplasm. ${ }^{11}$ The cytoplasmic localization and increased tyrosine kinase activity of bcr/abl induces the formation of multimeric protein complexes that may affect cellular proliferation, adhesion, and apoptosis, eventually leading to transformation. ${ }^{9}$ These complexes with bcr/abl include the adapter pro- 
teins, grb2 and crkL, the focal adhesion proteins, paxillin and talin, and the ras-activating proteins, shc and p62 dok..$^{6,14-18}$

Most of our understanding of abl transformation is based on results obtained through in vitro transformation assays using fibroblasts or factor-dependent hematopoietic cell lines. It is not clear if these assays are relevant to CML, because this disease arises in an early hematopoietic progenitor cell. In addition, the in vitro assays have often given contradictory results. For example, the Y177F mutation in bcr/abl abrogates fibroblast transformation but confers factor independence on factordependent cell lines. ${ }^{6,7,19}$ Results such as these have made it difficult to evaluate the contribution of certain bcr/abl domains to transformation.

One approach for investigating CML that is relevant to the disease is to use primary human tissue for study. Studies of this sort have shown that primary tissue has fewer phosphorylated proteins than cell lines and have turned the focus to several proteins that are highly phosphorylated in patients with CML, such as p62 dok and crkL. ${ }^{18,20}$ A major deficiency in using patient tissue to study the pathogenesis of CML is that relevant functional assays do not exist. One promising methodology for identifying the CML reservoir cell is to transfer human cells into SCID-NOD mice, as has been successfully performed to identify the cell type causing AML. ${ }^{21}$ A recent report shows that CML cells engraft at low frequency in NOD/SCID mice 22 ; however, the utility of this assay for studying the pathogenesis of CML has not been proven.

The deficiencies of the in vitro assays and the lack of a functional assay using human cells has driven the search for a murine CML model that accurately recapitulates this disease. Although creation of transgenic mice that express bcr/abl would be an excellent system, many of these transgenic strains develop acute leukemias without evidence of a myeloproliferative disease. ${ }^{23-25}$ A recent report suggests that expression of P210 bcr/abl via the tec promoter in transgenic mice may cause a myeloproliferative disease and blast transformation. ${ }^{26}$ One major drawback to this potentially useful system is that the latency period of the disease is greater than 1 year. ${ }^{26} \mathrm{In}$ addition, the penetrance of either the myeloproliferative disease or blast crisis has not been determined.

To date, the only approach that successfully recapitulates both the myeloproliferative and blast crisis phases of CML is a retroviral transduction model. ${ }^{27}$ In this model, introduction of P210-infected bone marrow into lethally irradiated syngeneic recipients caused a myeloproliferative disease resembling human CML. ${ }^{28-32}$ The mice developed very high WBC counts consisting primarily of cells of the granulocytic lineage, splenomegaly, and extramedullary hematopoiesis (EMH). In a small number of cases, it was possible to serially passage disease to syngeneic recipients. Some of these recipients developed neoplasms resembling blast crisis. Analysis of the proviral integration patterns in the mice with myeloproliferative syndromes and mice with acute leukemias/lymphomas showed identical proviral integration sites, which suggested that the disease arose in a hematopoietic progenitor cell.

Although it was hoped that these earlier retroviral transduction models would be useful for studying the pathogenesis of CML, limitations became apparent. ${ }^{27}$ First, the murine disease was not reliably induced because of difficulties in generating high-titer bcr/abl-expressing retroviruses. Second, the incidence of the myeloproliferative disease in transplant recipients was low, typically $20 \%$, even when viral titers were relatively high $\left(>5 \times 10^{5}\right)$. Third, serial transfer of the myeloproliferative disease occurred at a low frequency. ${ }^{30,32}$ The combination of these deficiencies greatly limited the use of these earlier murine CML models as a functional assay.

In this report, we describe a murine CML model that successfully overcomes the limitations of previous retroviral transduction models. We are able to induce a myeloproliferative disease that resembles many aspects of human CML in $100 \%$ of recipient mice by 4 weeks after transfer of P210 bcr/abltransduced bone marrow cells. In many cases, it is possible to serially passage the disease for up to 3 rounds. In all cases of serial passage, the myeloproliferative disease transforms into a lymphoid neoplasm, whose proviral integration pattern is identical to that in the primary myeloproliferative disease. This suggests that the disease arises in a myeloid/lymphoid progenitor cell. The consistency and rapidity of disease onset together with the ability to induce blast transformation should allow this murine model to be used for studying the pathogenesis of CML in a setting that is relevant to the human disease.

\section{MATERIALS AND METHODS}

Retroviral vectors and constructs. MSCV 210 was constructed by ligating the 7.2-kb EcoRI fragment containing the bcr/abl cDNA from pGD210 28 into MSCV2.2. ${ }^{33}$ MSCV Grb2 was constructed by amplifying the myc-tagged grb2 $\mathrm{cDNA}^{34}$ to which an $\mathrm{Xba}$ I site was added at the $3^{\prime}$ end and subcloning this into the Nco I-Xba I site of pCITE (Novagen, Madison, WI). The $1.5 \mathrm{kB}$ EcoRI-Sal I fragment containing the encephalomyocarditis virus (EMCV), internal ribosomal entry site (IRES), and grb2 cDNA was then cloned into the identical restriction fragment sites in MSCV2.2. The enhanced green fluorescent protein (eGFP)-expressing retroviral vector, MigR1, was constructed by threeway ligation with the 5-kb EcoRI-Sal I cleaved MSCV2.2, the 0.5-kb IRES containing EcoRI-Nco I fragment from pCITE, and the 0.8-kb Nco I-Sal I fragment containing a GFP with solubility and red shift mutations (J. Jacob, unpublished data). Mig210 was constructed by ligating the 7.2-kb EcoRI bcr/abl cDNA ${ }^{28}$ into MigR1.

Retroviral production and bone marrow infection protocols. Transfection of the retroviral vectors, cocultivation with 5-fluorouracil (FU)-treated bone marrow, and injection into lethally irradiated Balb/c recipients were performed as previously described. ${ }^{35}$ For experiments using MSCV 210, MSCV 210/grb2, and MSCV grb2, transduction of bone marrow cells was performed by cocultivation with transfected Bosc23 cells. Cocultivation of the transfected Bosc23 cells and 5-FU-treated bone marrow was performed in a cocktail consisting of Dulbecco's Modified Eagle medium (DME), 10\% heat-inactivated fetal bovine serum (JRH, Lenexa, KS), 5\% WEHI-conditioned medium, 6 $\mathrm{U} / \mathrm{mL}$ recombinant mouse interleukin-3 (IL-3; Genzyme, Cambridge, MA), $10,000 \mathrm{U} / \mathrm{mL}$ recombinant mouse IL-6 (Genzyme), $5 \mathrm{U} / \mathrm{mL}$ recombinant mouse stem cell factor (SCF; Amgen, Thousand Oaks, CA), $4 \mu \mathrm{g} / \mathrm{mL}$ polybrene (Sigma, St Louis, MO), $100 \mathrm{U} / \mathrm{mL}$ streptomycin (GIBCO, Grand Island, NY), $100 \mathrm{U} / \mathrm{mL}$ penicillin (GIBCO), and 2 $\mathrm{mmol} / \mathrm{L}$ L-glutamine (GIBCO). Between $2.5 \times 10^{5}$ and $5 \times 10^{5}$ nonadherent cells were injected into a tail vein of each lethally irradiated syngeneic recipient mouse. 5-FU-treated bone marrow cells were transduced by spinoculation ${ }^{36}$ for the experiments using the MigR1 and Mig210-derived retroviral supernatants. For these experi- 
ments, bone marrow cells, which were obtained 4 days after 5-FU treatment, were cultured for 24 hours in the above-described cocktail at a density of $1 \times 10^{6}$ cells $/ \mathrm{mL}$. The following day, $4 \times 10^{6}$ cells were added to a well of a 6 -well dish containing $3 \mathrm{~mL}$ of the infection cocktail and $1 \mathrm{~mL}$ of thawed, previously frozen retroviral supernatant. Spinoculation was performed as described, ${ }^{37}$ after which the cells were returned to the incubator. Twenty-four hours later, a second round of spinoculation was performed and the cells were returned to the incubator for 8 to 16 hours. At this point, $1.25 \times 10^{5}$ to $2.5 \times 10^{5}$ cells were injected into the tail veins of lethally irradiated syngeneic recipient mice. For serial transplants, spleen or bone marrow cells from diseased mice were injected into sublethally (450 rad) irradiated syngeneic mice. Balb/C mice were obtained from Taconic Farms (Germantown, NY). Comparison of cocultivation and spinoculation for bone marrow transduction (assayed using MSCV 210/grb2) showed that there was no difference in disease latency and phenotype between these two methods (not shown).

Flow cytometry. Cells obtained from peripheral blood, spleen, bone marrow, liver, or lymph node were analyzed for forward scatter (FSC), side scatter (SSC), and expression of GFP, Gr1, Mac1, Ter119, B220, Thy1.2, CD4, and CD8 by multiparameter flow cytometry as described. $^{38}$ Antibodies used were as follows: CD8a-biotin (53-6.7; Pharmingen, San Diego, CA), CD4-phycoerythrin (PE) (RM4-5; Pharmingen), TCR $\beta$-PE (H57-597; Caltag, South San Francisco, CA), Thy1.2biotin (53-2.1; Pharmingen), B220-biotin (RA3-6B2; Pharmingen), MAC1-biotin (M1/70; Pharmingen), Ter119-biotin (Pharmingen), and Gr1-biotin (RB6-8C5; Pharmingen). Dead cells were identified by propidium iodide staining as described. ${ }^{38}$ Fluorescence was analyzed on a FACScan flow cytometer with CellQuest software (Becton Dickinson, San Jose, CA).

DNA analysis. High molecular weight DNA was isolated from fresh or snap-frozen tissues, digested with appropriate restriction enzymes, and analyzed by Southern blot hybridization as previously described. ${ }^{35}$ Hybridization probes were the cDNA for neomycin resistance or the 592-bp ECMV IRES.

Immunoblotting and immunohistochemistry. Tissues were minced and single-cell suspensions were prepared in phosphate-buffered saline (PBS) in the presence of aprotinin (Sigma), benzamadine (Sigma), and Pefabloc SC (Boerhinger Mannheim, Indianapolis, IN). Cells were lysed in $2 \times$ sodium dodecyl sulfate-polyacrylamide gel electrophoresis (SDS-PAGE) sample loading buffer and separated by electrophoresis. The abl-specific antibody was 8E9 (Pharmingen). Cytospin slides were prepared from peripheral blood using standard hematologic techniques. Briefly, the slides were fixed in 3\% paraformaldehyde/PBS for 10 minutes, rinsed twice with PBS, and then permeabilized with $0.3 \%$ Triton X-100/PBS for 10 minutes. After rinsing twice with PBS, the slides were blocked for 30 minutes with blocking buffer consisting of $0.05 \mathrm{~mol} / \mathrm{L}$ Tris- $\mathrm{HCl}(\mathrm{pH} 7.6) / 0.14 \mathrm{~mol} / \mathrm{L} \mathrm{NaCl} / 1 \%$ bovine serum albumin (BSA) fraction $\mathrm{V} / 5 \%$ normal goat serum. The blocking solution was then drained off the slide and a 1:100 dilution of primary antibody against c-abl (24-11; Santa Cruz, Santa Cruz, CA) was applied for 1 hour. The slides were then washed in PBS for 10 minutes and drained, and secondary antibody was applied (1:100 dilution of AP conjugated goat antimouse IgG1 [Jackson Immunochemicals, West Grove, PA] in blocking buffer) for 30 minutes. The slides were then washed in PBS for 10 minutes and drained, and a 1:1 mixture of stable fast red and stable napthol phosphate (Research Genetics, Huntsville, AL) was applied for 10 minutes. The slides were rinsed in deionized water and counterstained with hematoxylin. The slides were visualized under bright field and fluorescence microscopy using the rhodamine filter set. Positive and negative controls consisted of cytospins of FL512 cells previously transduced with Mig210 retrovirus and untransfected FL512 cells, respectively.

\section{RESULTS}

MSCV210 induces a myeloproliferative disease in 100\% of recipient mice within 6 weeks of bone marrow transfer. We believed that the low induction frequency and possibly the long latency in existing mouse models of CML were caused by low transduction rates of appropriate hematopoietic progenitors. Multipotent hematopoietic progenitor cells are rare in the bone marrow population, ${ }^{39}$ and retroviruses must be of sufficient titer to infect these rare cells. To consistently generate high-titer $\mathrm{P} 210$ bcr/abl-expressing retroviruses, we used Bosc23 retroviral packaging cells. Bcr/abl retroviral supernatants obtained after transfection of Bosc 23 cells had infectious titers in excess of $1 \times 10^{6}$ infectious units/mL, as assayed by either G418 resistance or GFP expression..$^{40}$ To improve the likelihood that the transduced hematopoietic progenitors would express the provirus, the MSCV retroviral vector was used to express the P210 bcr/abl cDNA (Fig 1A). ${ }^{33}$ For transduction of hematopoietic progenitors, this vector offers the advantages of (1) expressing cloned cDNAs from the murine stem cell retroviral LTR that has been shown to express at high levels in embryonic carcinoma and embryonic stem cells and (2) the presence of an extended packaging site for maximal retrovirus production. In conjunction, the bone marrow transduction conditions were altered by including murine stem cell factor in the transduction medium, ${ }^{41}$ preincubating the donor bone marrow cells for 24 hours before retroviral transduction, ${ }^{42}$ and either including additional retroviral supernatant in the coculture medium ${ }^{32}$ or transducing the bone marrow cells by spin infection (spinoculation). ${ }^{36}$ These latter changes were made to enhance transduction of increased numbers of cycling hematopoietic progenitors.

High-titer retroviral supernatants (at least $1 \times 10^{6} \mathrm{G} 418$ resistant NIH3T3 colonies $/ \mathrm{mL}$ ) were prepared by transfecting Bosc23 cells with MSCV 210. In our initial experiments (and all experiments using MSCV 210, MSCV 210/grb2, and MSCV grb2), bone marrow cells obtained from 5-FU-treated Balb/c mice were cocultured with the transfected Bosc 23 cells for 48 hours, beginning 24 hours after transfection (Fig 1B). For the entire 72-hour period, the donor bone marrow cells were cultured in medium containing IL-3, IL-6, SCF, and 5\% WEHI-conditioned medium. Freshly thawed high-titer retroviral supernatant was also added to the transduction medium at 24 and 48 hours after transfection. After the 48-hour cocultivation, nonadherent cells were removed and injected into lethally irradiated syngeneic recipients. Between 21 and 31 days, each mouse developed cachexia, decreased movement, and poor grooming (Fig 2). Peripheral WBC counts were also elevated $\left(>35 \times 10^{6} / \mathrm{mL}\right)$ in the recipient mice (Table 1 and Fig $3 \mathrm{~A}$ and B). In all mice, differential counts showed that the cells in the peripheral blood were largely composed of mature granulocytes, consisting of polymorphonuclear neutrophils (PMNs) and metamyelocytes (Fig 3C). Blasts were rare and, when present, did not account for greater than $3 \%$ of the WBC. Basophils were rarely present in the peripheral blood. In some mice, a significant percentage of nucleated red blood cells were present. In contrast to mice receiving P210-transduced bone marrow cells, the peripheral WBC of mice receiving bone marrow cells transduced with a control retroviral vector was largely composed of mature lymphocytes. With the onset of 
A.

A. MSCV 210

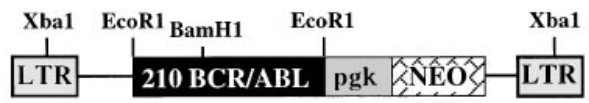

B. MSCV 210/Grb2

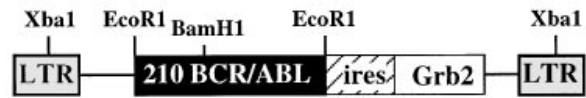

C. MIG210

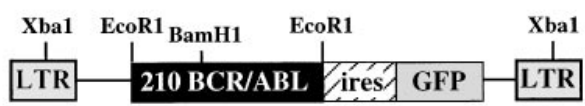

D. MSCV Grb2

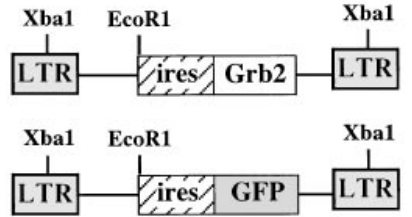

Fig 1. (A) Structure of the retroviral vectors used to transduce murine bone marrow. The LTRs and vector backbone for all constructs was MSCV2.2. The EcoRI and Xba I restriction enzyme sites used for determining proviral integration are indicated. (B) Protocol for retroviral transduction of FU-treated bone marrow and subsequent reconstitution. During the 48-hour cocultivation, retroviral supernatants were added to the media (1 $\mathrm{mL}$ every 24 hours) or cells were transduced by spin infection without cocultivation (see Materials and Methods).
E. MIG R1

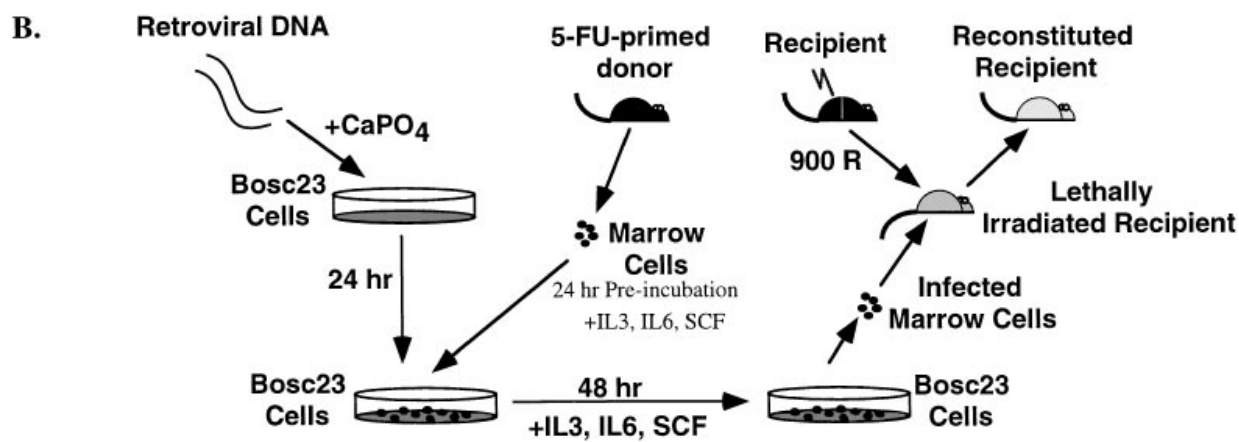

these triad of changes (elevated WBC, decreased activity, and cachexia), the mice were euthanized and analyzed for gross and histopathologic changes and the presence of provirus.

The pathologic changes found at necropsy of mice receiving P210-transduced bone marrow were remarkably consistent, principally stemming from increased numbers of maturing hematopoietic cells within the bone marrow and extramedullary tissues. The spleens were red, firm, and enlarged, with weights 3 to 5 times greater than control animals (Tables 1 and 2 and Fig 3D). Histologic examination showed marked expansion of the splenic red pulp and partial to complete replacement of the splenic white pulp by hematopoietic elements, mostly consisting of mature and immature granulocytes admixed with variable numbers of immature nucleated erythroid cells and megakaryocytes (Fig 3E). In some spleens, foci of necrosis of up to $0.5 \mathrm{~mm}$ in size were present that appeared to represent areas of infarction. The bone marrow was hypercellular (no residual fat cells), with most of the cellularity consisting of maturing granulocytes and scattered megakaryoctyes (Fig 3F). The livers were enlarged and firm, and histologic examination showed extensive EMH within sinusoids and around portal tracts and central veins (Fig 3G). Similar to the spleen, the liver contained immature and mature granulocytes, foci of erythropoiesis, and megakaryocytes. In addition, 10 of 11 animals receiving MSCV 210 bone marrow cells exhibited a focal perivascular expansion of macrophages, primarily confined to the liver (Fig $3 \mathrm{H}$ ). In

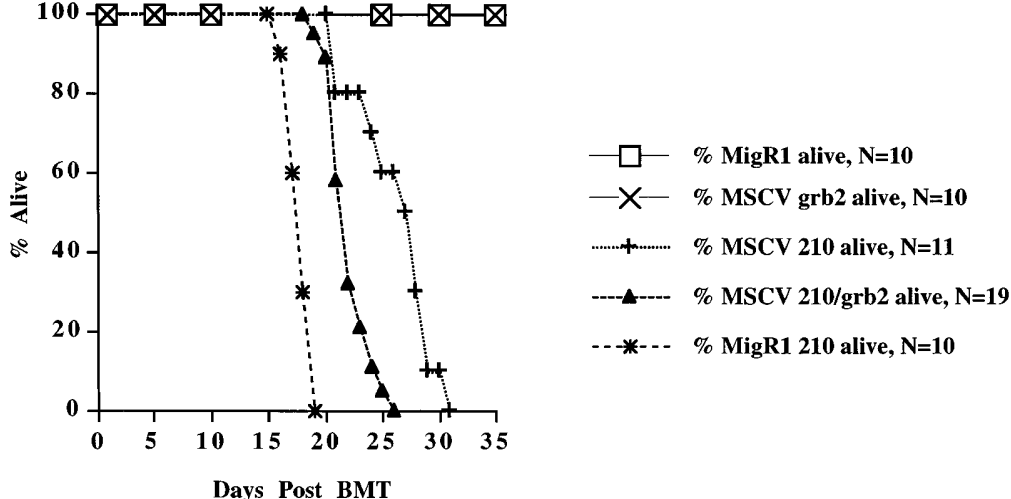

Fig 2. Survival of mice receiving transduced bone marrow cells. The survival data are cumulative from two separate experiments for all retroviral constructs, except MSCV 210, which are from one experiment. 
Table 1. Summary of murine P210 bcr/ abl bone marrow transfer experiments

\begin{tabular}{|c|c|c|c|c|c|c|c|c|}
\hline Construct & $\begin{array}{c}\text { No. of } \\
\text { Independent, } \\
\text { Experiments }\end{array}$ & $\begin{array}{c}\text { No. of } \\
\text { Evaluable } \\
\text { Mice }\end{array}$ & $\begin{array}{c}\text { No. of Mice } \\
\text { With Murine } \\
\text { CML }\end{array}$ & $\begin{array}{l}\text { Latency } \\
\text { (d) }\end{array}$ & $\begin{array}{c}\text { WBC Range } \\
\left(\times 10^{6} \text { cells } / \mathrm{mL}\right)\end{array}$ & $\begin{array}{l}\text { Spleen Weight } \\
\text { Range in Grams }\end{array}$ & $\begin{array}{c}\text { \% With } \\
\text { Pulmonary } \\
\text { Involvement }\end{array}$ & $\begin{array}{c}\text { \% With } \\
\text { Macrophage } \\
\text { Foci }\end{array}$ \\
\hline MSCV 210 & 1 & 11 & 11 & $21-31$ & $36-265$ & $0.6-0.9$ & 100 & 91 \\
\hline MSCV 210/grb2 & 2 & 19 & 19 & $19-26$ & $50-160$ & $0.6-0.9$ & 100 & 47 \\
\hline Mig 210 & 2 & 10 & 10 & $16-19$ & $60-390$ & $0.6-0.75$ & 100 & 20 \\
\hline
\end{tabular}

The results summarize five independent experiments. For MSCV 210/grb2, 23 mice were reconstituted; however, 4 mice died before analysis and tissue degradation precluded diagnosis. Latency is defined as either time to death or time to onset of terminal symptoms consisting of cachexia, decreased activity, and hunched posture with tachypnea. For control mice transduced with either MigR1 or MSCV grb2, the WBC ranged from 5 to $15 \times 10^{6} / \mathrm{mL}$ cells during this period and spleen weights were 0.1 to 0.25 grams.

addition, there was marked pulmonary hemorrhage in all of the MSCV 210 mice. Microscopically, areas of hemorrhage were frequently associated with foci of extramedullary hematopoiesis, predominantly consisting of maturing granulocytes (Fig 3I). There was no evidence of thymic enlargement or lymphadenopathy in the P210 animals.

Two other P210-expressing retroviral vectors, MSCV 210/ grb2 and Mig210, were also used to transduce bone marrow cells (Fig 1A). Like MSCV 210, both of these vectors expressed P210 from the MSCV LTR, but, in contrast, both vectors expressed a second protein via the ECMV IRES rather than an internal promoter. The use of the ECMV IRES results in a bicistronic message that is independently translated. This strategy increases the likelihood that both proteins will be expressed in transduced cells by alleviating the effects of promoter competition, which frequently causes downregulation of protein expression in internal promoter vectors. ${ }^{43}$ MSCV 210/grb2 coexpresses P210 and grb2, whereas Mig210 coexpresses P210 and GFP. The former vector was originally constructed to assess the effects of coexpressing P210 and grb2 on development of the murine disease (Pear et al, manuscript in preparation) and the latter vector was developed to use GFP as a surrogate marker to identify P210-transduced cells. Coexpression of P210 and grb2 appears to have little effect on the P210-induced disease, because MSCV 210/grb2 causes a myeloproliferative disease with an identical phenotype to Mig210 and MSCV210 (not shown). The disease latency was slightly shorter in experiments using either the Mig210 or MSCV 210/grb2 vectors (Table 1 and Fig 2). This difference may be due to the lack of promoter competition in the bicistronic vectors.

P210 is expressed in involved tissues. To evaluate expression of the introduced bcr/abl protein, immunofluorescent and immunoblotting studies were performed. Cytospin preparations from involved organs showed P210 expression in myeloid cells, nucleated erythroid cells, and megakaryocytes using an indirect immunofluorescent assay with an abl-specific monoclonal antibody (Fig $3 \mathrm{~K}$ through $\mathrm{N}$ and not shown). To show that the correctly sized protein was expressed, lysates prepared from spleen, liver, bone marrow, and peripheral blood were analyzed by Western blot with an abl-specific antibody. All tissues showed high levels of expression of the expected $210-\mathrm{kD}$ bcr/abl protein (Fig 4).

Analysis of P210-transduced cells in vivo demonstrates that the majority of cells are myeloid in origin. Further evaluation of the effects of P210 expression was facilitated by use of GFP as a surrogate marker. In Mig210, GFP is coexpressed with
P210 as a bicistronic message. Thus, tissues that express GFP should also express P210. This was confirmed by cytospin preparations in which bcr/abl-expressing cells also expressed GFP (not shown). Use of the Mig210 retroviral vector has allowed immunophenotyping of the involved tissues, as described below (Fig 5). The majority of cells in peripheral blood, spleen, bone marrow, and liver expressed GFP. In all Mig210 mice analyzed by flow cytometry, the GFP-expressing cells were contained within a single sharp peak on the GFP histogram (Fig 5, column 2), suggesting the possibility that many of the cells were derived from a single clone (see below). In peripheral blood, spleen, and bone marrow, the great majority of GFPexpressing cells coexpressed the myeloid-specific markers, Gr1 and Mac1 (Fig 5, columns 3 and 4). Most of the cells in the peripheral blood expressed high levels of both Gr1 and Mac1, features of mature granulocytes. In contrast, cells in the spleen, bone marrow, and liver expressed Gr1 over a wide range, consistent with the presence of both mature and immature myeloid cells in these tissues. ${ }^{44} \mathrm{~A}$ small percentage of $\mathrm{B} 220^{\mathrm{lo}} /$ $\mathrm{GFP}^{+}$cells were present in all tissues (Fig 5, column 5). There were very few Thy 1.2/GFP-positive cells in any organ, possibly because these mice died before the occurrence of T-cell reconstitution (Fig 5, column 6). Both liver and spleen contained a significant number of Ter119/GFP positive cells, consistent with the histologic observation that the bulk of erythropoiesis occurred in these tissues (Fig 5, column 7).

The immunophenotypes of cells obtained from mouse tissues after reconstitution with bone marrow cells transduced by the control GFP-expressing retroviral vector, MigR1, were very different than the immunophenotypes described above (Fig 5). A lower percentage of cells in all organs expressed GFP (Fig 5, column 2). In addition, unlike the single peak present in the GFP histograms of the Mig210 mice, there was a much broader pattern of GFP expression in tissues from the MigR1 mice (Fig 5, column 2). In comparison to Mig210 mice, there was a much lower percentage of myeloid cells in the spleen and a greater percentage of $\mathrm{B}_{22} 20^{+} / \mathrm{GFP}^{+}$cells (Fig 5, columns 3, 4, and 5). B220 expression was higher in the B cells in both the spleen and bone marrow as compared with the $\mathrm{P} 210$ mice.

All affected tissues contain P210 proviral DNA. To demonstrate that the tumors contained an intact provirus, DNA was digested with $X b a$ I and probed with either IRES sequences (MSCV 210/grb2 or Mig210) or the neo gene (MSCV 210). All tumors contained the single expected 9-kb (MSCV 210) or 8.8-kb (Mig210 or MSCV 210/grb2) band demonstrating an intact provirus (not shown). To enumerate the proviruses, DNA 


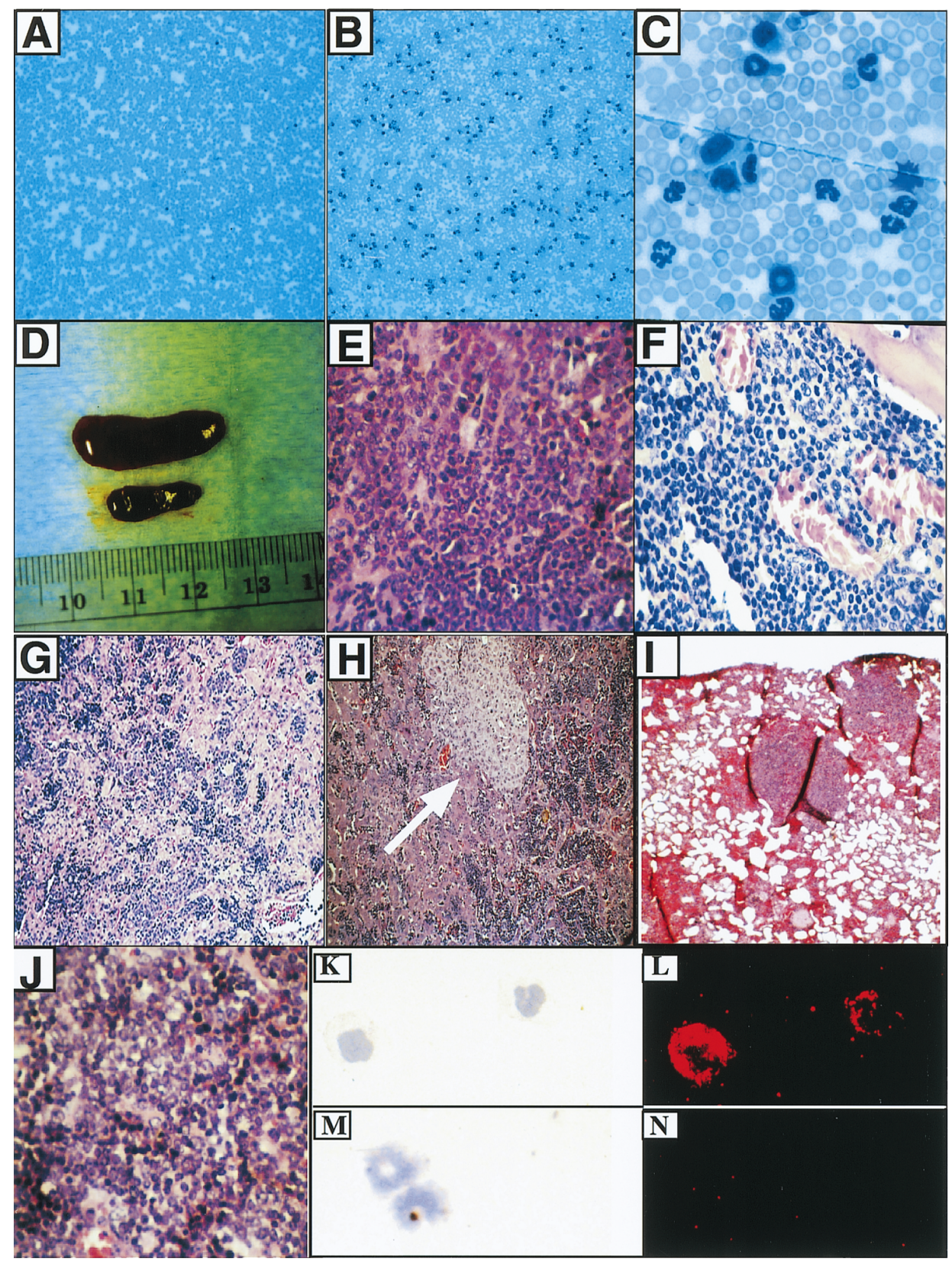

Fig 3. Characteristics of the P210-induced myeloproliferative disease. (A) Peripheral blood from a mouse transduced with a control retrovirus (MigR1). Original magnification $\times 100$. (B) Typical appearance of peripheral blood from mouse with myeloproliferative disease. Original magnification $\times 100$. (C) Higher power view of (B). Original magnification $\times 1,000$. (D) Splenomegaly associated with myeloproliferative disease. The diseased spleen is on top and the spleen from a MigR1 control animal is below. (E) Hematoxylin and eosin (H\&E) section of spleen from (D). The red pulp is replaced by sheets of granulocytes. Original magnification $\times 400$. (F) Hypercellular murine CML bone marrow. The great majority of cells are mature granulocytes. Original magnification $\times 400$. (G) Liver in murine CML shows infiltration of mature myeloid cells and EMH in sinusoids. Original magnification $\times \mathbf{1 0 0}$. This mouse did not have the macrophage expansion. (H) Murine CML liver with macrophage expansion (arrow). Note infiltrating hematopoietic cells in sinusoids. Original magnification $\times$ 400. (I) Pulmonary infiltrates of EMH in P210 mice. Original magnification $\times 100$. ( ) T-cell lymphoma associated with blast transformation (from an abdominal mass). Original magnification $\times 400$. This tumor developed after 2 rounds of serial transplant of the myeloproliferative disease from mouse H2. (K) Wright-Giemsa staining of cells from peripheral blood of mouse receiving Mig210-transduced bone marrow cells. Original magnification $\times 400$. (L) Abl expression in the cells from (K) as detected by the abl monoclonal antibody 24-11. Original magnification $\times 400$. (M) Wright-Giemsa staining of cells from peripheral blood of mouse receiving Mig210-transduced bone marrow cells. Original magnification $\times 400$. (N) Staining with an isotype control. Original magnification $\times \mathbf{4 0 0}$. 
Table 2. Disease Characteristics of Murine CML

\begin{tabular}{lcclc}
\hline Mouse & $\begin{array}{c}\text { Latency } \\
\text { (wks) }\end{array}$ & WBC & \multicolumn{1}{c}{ Differential Count } & $\begin{array}{c}\text { Spleen } \\
\text { Weight }(g)\end{array}$ \\
\hline Grb2 & - & 15 & 45P/50L/5M & 0.2 \\
H20 & 4 & 75 & 84P/5L/3M/6NR & 0.6 \\
H21 & 4 & 100 & 73P/11L/1M/11NR & 0.8 \\
H22 & 3 & 77 & 69P/7L/3M/9NR & 0.6 \\
H23 & 4 & 77 & 80P/7L/2M/1NR & 0.6 \\
H24 & 3 & 36 & 51P/9L/1M/36NR/3Blasts & 0.7 \\
H25 & 4 & 265 & 86P/2L/1M/11NR & 0.9 \\
H26 & 4 & 250 & 90P/3L/2M/1NR & 0.75 \\
H27 & 3 & 53 & ND & 0.6 \\
H28 & 4 & 220 & 79P/13L/3M/5NR & 0.8 \\
H29 & 3 & 200 & 76P/4L/20NR & 0.85 \\
\hline
\end{tabular}

Characteristics of the P210-induced myeloproliferative disease in one transplant experiment. Disease was induced by transduction with MSCV 210 (see Table 1). Grb2 is a mouse that received MSCV Grb2, which only expresses grb2. This mouse (as did all MSCV Grb2 mice) remained healthy for the entire 9-month observation period. WBC count is $10^{6}$ cells $/ \mathrm{mL}$. For the differential counts, $\mathrm{P}$ indicates polymorphonuclear granulocytes, $\mathrm{L}$ indicates lymphocytes, $\mathrm{M}$ indicates monocytes, NR indicates nucleated red blood cells, and ND indicates not determined.

was digested with EcoRI and probed with either IRES sequences (Fig 6A through D and F) or neo sequences (Fig 6E). The number of integrated proviruses ranged from one (Fig 7B) to seven (Fig 6E, lane 3). The number of proviral integration

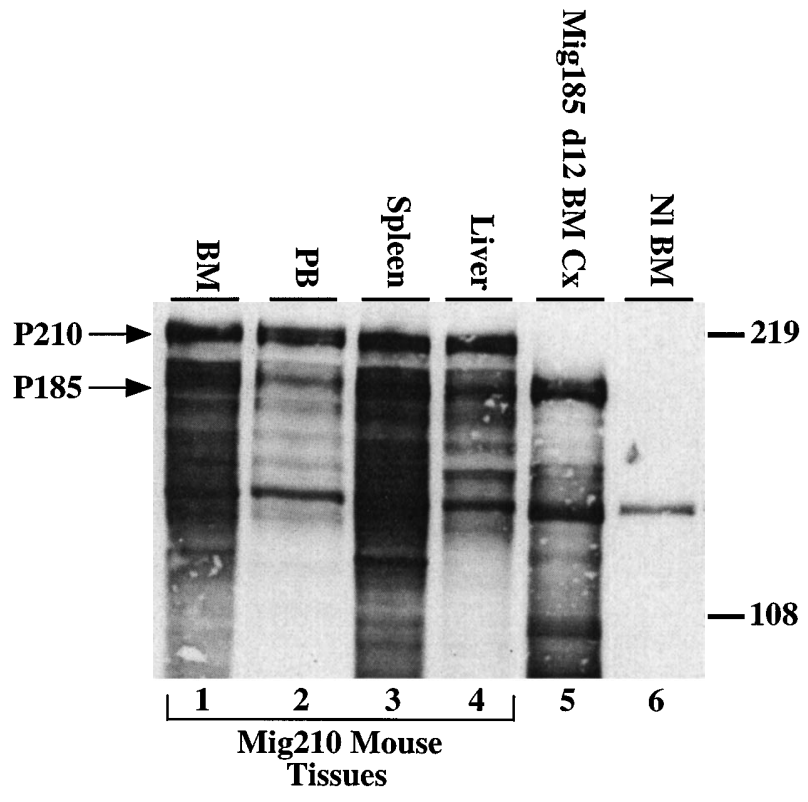

Fig 4. P210 bcr/abl is expressed in tissues involved in the myeloproliferative process. Cells $\left(5 \times 1^{6}\right)$ were loaded per lane and detected with the 8E9 abl-specific monoclonal antibody (Pharmingen). Many of the lower molecular weight bands are most likely the result of proteolysis due to the high percentage of neutrophils in the cell lysates. ${ }^{28}$ Lanes 1 through 4, bone marrow, peripheral blood, spleen, and liver cells from a Mig210 mouse. Lane 5, day-12 cells from bone marrow cultures transduced with Mig185. Mig185 is similar to Mig210, except Mig185 expresses P185 bcr/abl (Miller and Pear, unpublished data). Lane 6, Balb/c bone marrow cells. The band at approximately $\mathbf{1 4 0} \mathbf{~ k D}$ in all lanes is c-abl. Arrows indicate the $\mathbf{2 1 0}$ and 185-kD proteins. sites did not appear to influence the disease, because all primary mice had a very similar disease latency and disease phenotype. In some mice with multiple proviruses, the proviral integrants were at levels comparable to a single copy of each per genome (G22, G40, G41, G42, G56, H27, BB14, and BB16). This finding suggests that the disease tissue arose from a single cell that had sustained multiple retroviral infections. Moreover, DNA prepared from different tissues from the same animal showed a similar proviral integration pattern (G40, G42, BB14, and BB16). In other mice with multiple proviruses, there were proviral integrants that did not show equal contribution from all clones (G21, G50, and H28). Because DNA was prepared from the entire tissue, it is possible that some of the tissues contained multiple different clones but that the majority of the cells were derived from a single clone.

Murine CML can be serially passaged before blast transformation occurs. Serial passage is important for studying disease progression in the murine CML model, because the myeloproliferative disease is rapidly fatal due to the extraordinary hematopoietic expansion. In addition, the ability to serially passage the disease allows determination of clonality and also gives further proof that the disease is a malignancy. In fact, there have been several cases in which murine myeloproliferative defects have been called CML models; however, the myeloid cells did not contain the provirus, suggesting that the granulocyte accumulation was a reactive process. ${ }^{45}$

In primary mice that develop murine CML, serial passage was performed by transferring either spleen or bone marrow cells (or both) to sublethally irradiated syngeneic mice. This resulted in the occurrence of hematopoietic malignancies in mice receiving 7 of 8 different primary tumors (Table 3 and not shown). For six of the primary tumors, it was possible to transmit the myeloproliferative disease for at least one round and the disease in the secondary recipients closely resembled the primary myeloproliferative disease, both in latency and phenotype. Recipients of G4 spleen and bone marrow cells developed a T-cell lymphoma with a latency of 12 to 16 weeks (Table 3). The T-cell lymphoma occurred in either the thymus or abdominal lymph nodes and its cells were Thy $1.2^{+} / \mathrm{CD}^{+} /$ $\mathrm{CD}^{+}$(not shown). Some of the secondary recipients of cells from G28 developed the myeloproliferative phenotype ( 3 of 4 secondary recipients), whereas one recipient developed acute lymphocytic leukemia (ALL) at 14 weeks after transfer as determined by histology. We were unable to immunophenotype this tumor, because the mouse died before workup.

In our most successful series of serial transplantation, it was possible to transfer the myeloproliferative disease to three generations of mice (Fig 6A). The myeloproliferative disease occurred with a latency period of 4 to 6 weeks in all mice and the phenotype of the disease was similar to that shown in Fig 3. In the third round of serial passage, recipients of mouse $\mathrm{H} 2 \mathrm{~A} 4$ developed T-cell lymphomas presenting as solitary abdominal masses that were Thy $1.2^{+} / \mathrm{CD}^{+} / \mathrm{CD}^{+}$(not shown). In contrast, all of the recipients of spleen cells from $\mathrm{H} 2 \mathrm{~A} 3$ developed the myeloproliferative disease. Serial passage of spleen cells from the H2A3B mice resulted in the development of T-cell lymphomas in tertiary serial transplant recipients (Fig 3J). The T-cell lymphomas were either thymic masses or abdominal masses and expressed the immature T-cell markers Thy 1.2/CD4/ 
A. Peripheral Blood
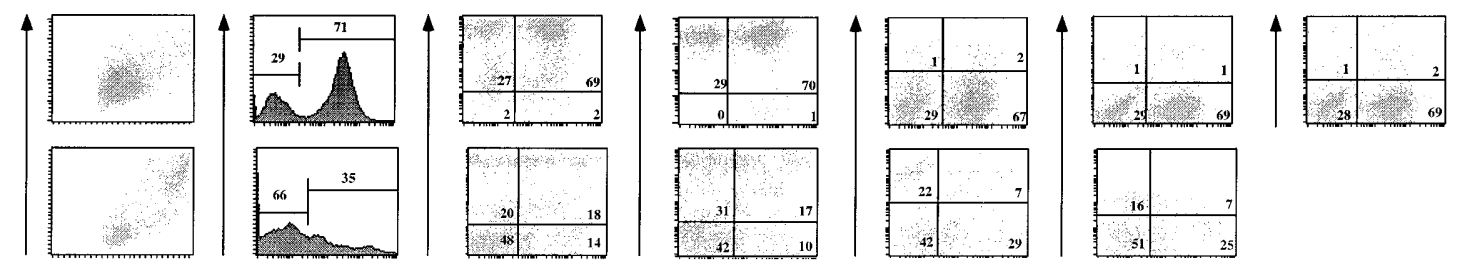

Retrovirus

Mig 210

Mig R1

(GFP)

B. Spleen
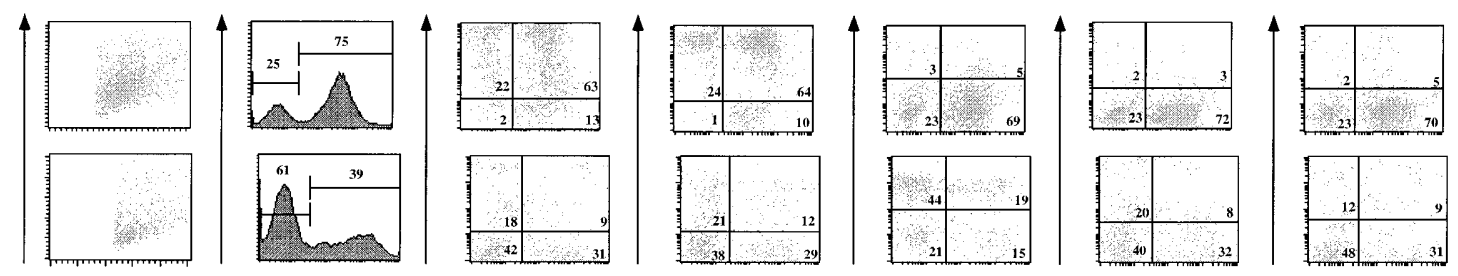

Mig 210

Mig R1

(GFP)

C. Bone Marrow
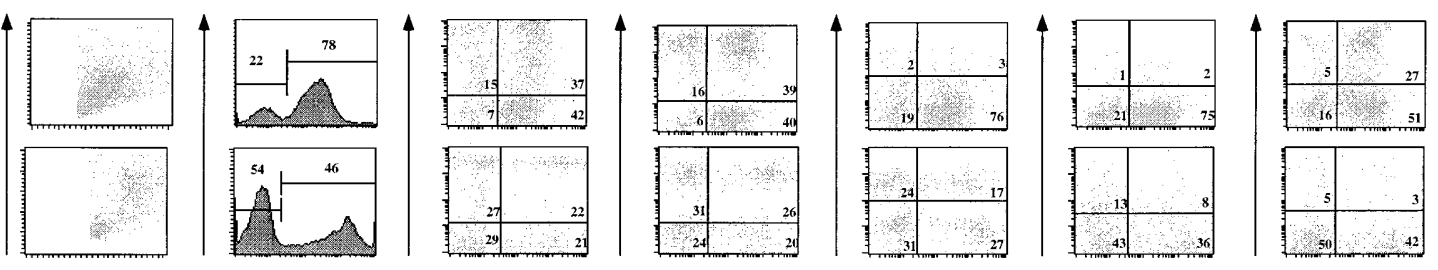

Mig 210

Mig R1

(GFP)

D. Liver

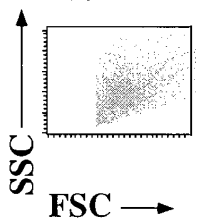

1

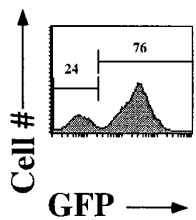

2

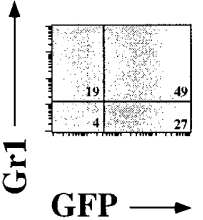

3

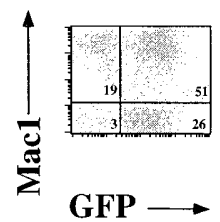

4

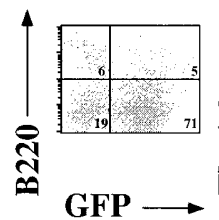

5

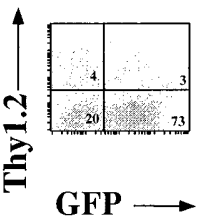

6

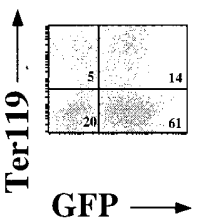

7

Fig 5. Immunophenotypes of cells obtained from peripheral blood, spleen, bone marrow, and liver of mice receiving either P210 (Mig210) or control (MigR1) bone marrow cells. Mig210 expresses both P210 bcr/ abl and GFP, whereas MigR1 expresses only GFP. GFP fluoresces in the FL1 channel. The lineage-specific antibodies (Gr1, Mac1, B220, Thy1.2, and Ter119) were directly or indirectly labeled with PE and fluoresce in the FL2 channel. Hematopoietic cells were not present in the livers of mice receiving MigR1. Ter119 staining was not performed on the cells derived from MigR1 peripheral blood. The Mig210 data were obtained from mouse BB12 and are a representative Mig210 phenotype. The MigR1 data were obtained from mouse FF4 and are a representative MigR1 phenotype.

CD8. Although serial passage of spleen cells resulted in the myeloproliferative disease in the $\mathrm{H} 2 \mathrm{~A} 3 \mathrm{~B}$ tertiary recipients, serial passage of $\mathrm{H} 2 \mathrm{~A} 3$ bone marrow cells caused only T-cell lymphomas in tertiary recipients (not shown).

The proviral integration pattern was analyzed to determine whether the myeloproliferative disease and T-cell lymphomas in the $\mathrm{H} 2$ mice were derived from the same precursor. To enumerate the proviruses present in the tissue samples, genomic DNA was digested with EcoRI and probed with the neo gene (Fig 7B and C). The $\mathrm{H} 2$ primary mouse contained a single proviral integrant of approximately $15 \mathrm{~kb}$ (Fig 7B, lanes 1 and 2). Affected tissues from secondary and tertiary mice that developed the myeloproliferative disease contained a single identical 15-kb proviral integration (Fig 7B, lanes 3 through 8, and 7C, lanes 5 through 7). A single, identical proviral integration was also present in the T-cell lymphomas (Fig 7C, lanes 2 through 4). This demonstrates that murine CML arises in a pluripotential hematopoietic cell that is capable of giving rise to both the myeloid and lymphoid lineages. To demonstrate that the tumors contained an intact provirus, DNA was digested with $\mathrm{Xba}$ I (which cleaves in both retroviral LTRs) and probed with the neo gene. The expected 9-kb band from MSCV 210 is present in all affected tissues from $\mathrm{H} 2$ mice (Fig 7D and not shown).

Analysis of the proviral integration pattern in other serial passage recipients showed that the identical proviral integration pattern that was present in the primary mice is also present in secondary and tertiary recipients of serially transplanted spleen and bone marrow cells (Fig 6B, lanes 1 through 4 and 7 through 11). In addition, spleen cells from G56 were transferred to lethally irradiated recipients for a day-12 colony-forming unit-spleen (CFU-S) assay and all individual spleen colonies contained intact, integrated proviral DNA (not shown). This suggests that the P210-transduced cell that caused the G56 myeloproliferative disease was also capable of giving rise to day-12 spleen colony-forming units.

\section{DISCUSSION}

We have developed an efficient and reproducible method for inducing a murine disease that recapitulates the cardinal features of human CML. This has resulted in the ability to induce 


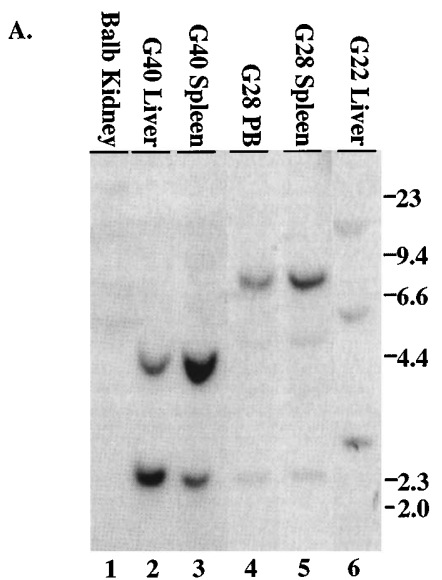

C.

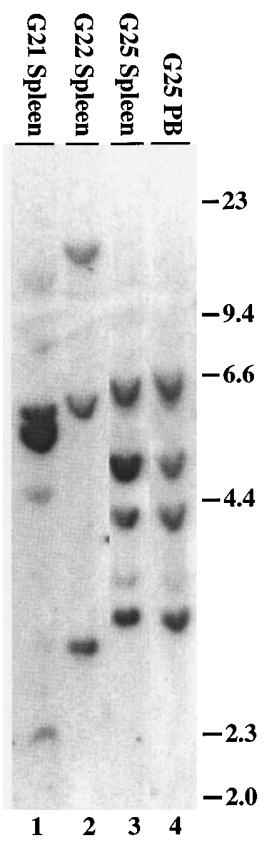

B.

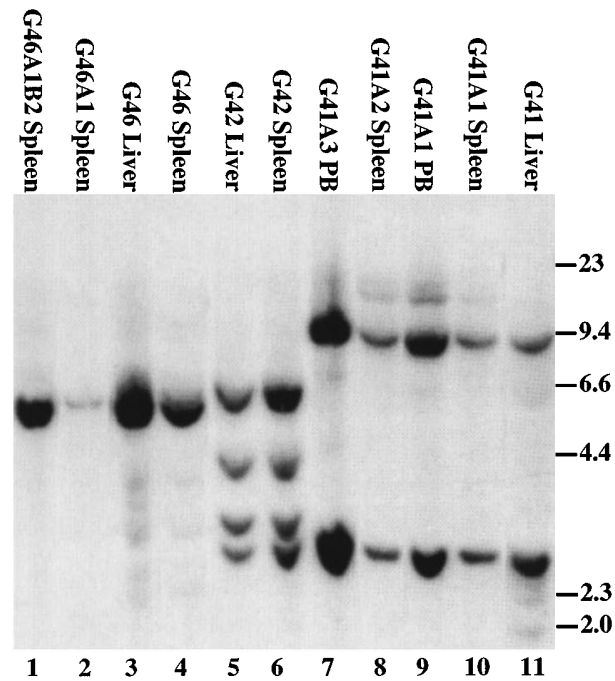

D.

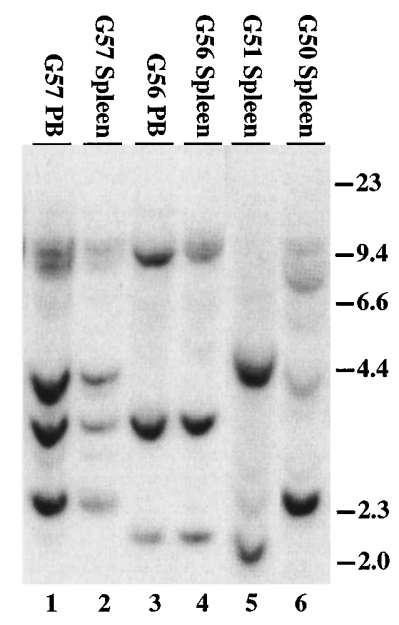

E.

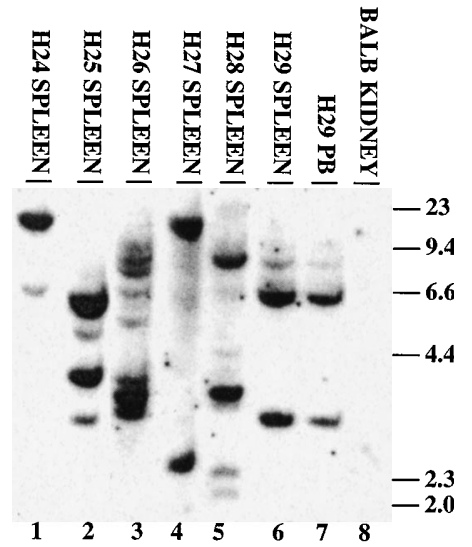

Fig 6. Proviral integration in P210 mice. (A through D) Tissues from mice receiving MSCV 210/grb2. (E) Tissues from mice receiving MSCV 210. (F) Tissues from mice receiving Mig210. All DNA preparations were digested with EcoRl except for lanes 1 and 3 in (F), which were digested with BamHI, which also cleaves once in the provirus. Digestion with $X$ ba I showed the presence of intact proviral DNA for all samples (not shown). All samples are from primary mice and labeled with the tissue from which the DNA was derived, except for the following in (B): lane 2, G46A1 spleen-secondary recipient of spleen cells from G46, this mouse developed the myeloproliferative disease; lane 1, G46A1B2 spleen: recipient of spleen cells from G46A1, this mouse developed T-ALL; lanes 9 and 10, G41A1 spleen and peripheral blood, G41A2 spleen, and G41A3 peripheral blood: recipient of spleen cells from G41; these mice developed the myeloproliferative disease. Abbreviations: PB, peripheral blood; B, BamHI; R1, EcoRI. Sizes of the $\lambda$ HindIII marker are shown.

murine CML in $100 \%$ of recipient mice with a latency of 4 to 6 weeks. Previous investigators have induced murine CML after transfer of bcr/abl-transduced bone marrow cells into lethally irradiated recipient mice. Although these studies showed that bcr/abl induced a CML-like disease in mice, the utility of the model was compromised by low induction frequencies and/or long latency periods. To overcome these problems, we introduced several changes into the transplant protocols. These included (1) consistent and reproducible production of hightiter bcr/abl retroviral supernatants, (2) use of the MSCV retroviral vector, and (3) changes in the bone marrow transduction milieu. Although high-titer retroviral production is a prerequisite for disease induction, the use of the MSCV retroviral vector and addition of stem cell factor to the transduction cocktail are likely to be important for efficient induction of murine CML. In contrast to the Moloney leukemia virus LTR, the MSCV LTR is capable of efficient gene expression in embryonic stem and carcinoma cells. ${ }^{46}$ Our results suggest that the MSCV LTR functions equally well in hematopoietic progenitors. In addition to the use of the MSCV LTR as a promoter, the use of an IRES rather than an internal promoter to express a second mRNA is associated with more efficient disease induction.

The 4- to 6-week latency period for disease development in 
Fig 7. Development of blast transformation after serial passage. (A) Cartoon showing disease development in recipients of cells from serial passage. Secondary recipients (A1 through 5) received a 1:1 mixture of spleen and bone marrow cells from mouse H2. Spleen or bone marrow cells were transferred to tertiary recipients. Only mice receiving the spleen cells developed the myeloproliferative disease. All mice receiving bone marrow cells developed T-cell lymphomas with characteristics similar to H2A4B1. Cells derived from the spleen of tertiary recipients that developed the myeloproliferative disease were transferred to quatemary recipients. All of these mice developed T-cell lymphomas. (B) Proviral integration pattem shows a common single proviral integration site in all H2 mice. Lanes 1 and 2 are from primary mice. Lanes 3 through 8 are from secondary mice. (C) Both the myeloproliferative disease and T-cell lymphomas show an identical proviral integration pattem. Lanes 2 through 4 are derived from T-ALL. Lanes 5 through 7 are secondary and tertiary recipients. (D) Tissues from the $\mathrm{H} 2$ mice show the presence of an intact integrated provirus. For (B) and (C), genomic DNA was digested with EcoRI and genomic DNA shown in (D) was digested with Xba I. The blots were hybridized with the cDNA expressing the neomycin resistance gene.
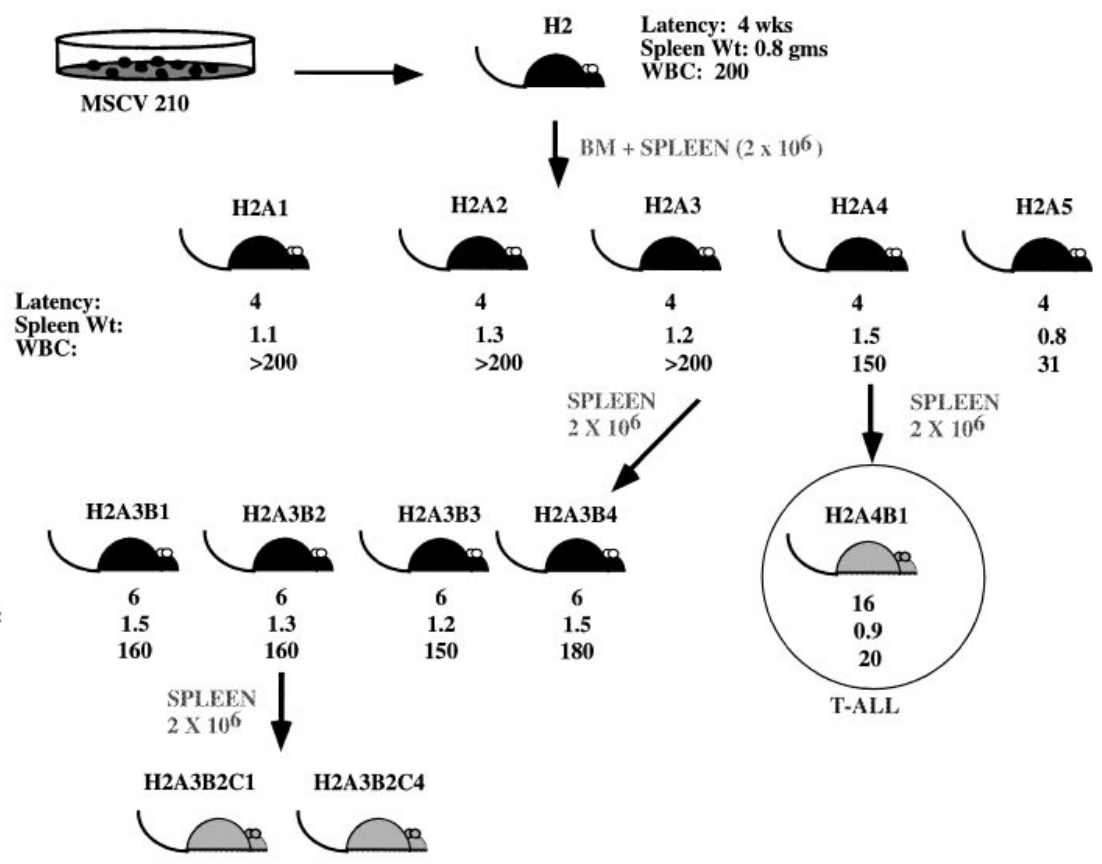

T-ALL: 16-20 week latency

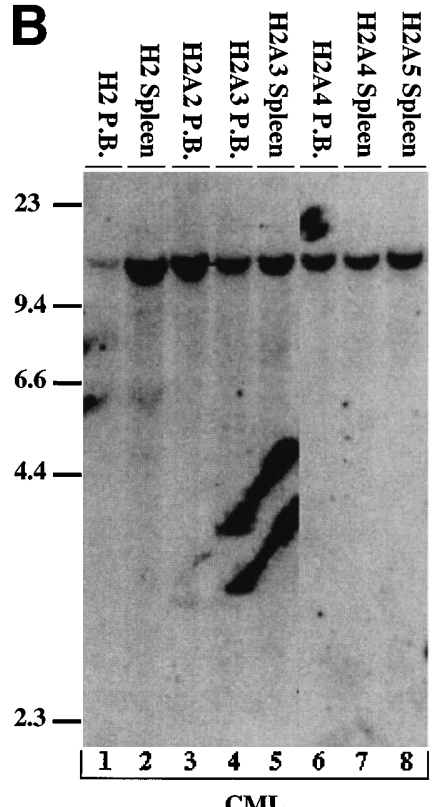

CML

C our model is shorter than that described in previous CML models, in which the average latency varied between 9 weeks and 1 year. ${ }^{28-32}$ Potential explanations for our decreased latency are (1) the changes in the culture conditions are putting the appropriate cell into cycle; (2) the increased retroviral titer increases transduction of the correct target cell; and/or (3) use of the MSCV LTR results in more efficient bcr/abl expression. One effect of the changes introduced into the methodology is to increase the number of proviral integrants. In previous reports, the majority of analyzed tumors had only a single proviral integration. ${ }^{28-32}$ In contrast, many of the tumors described in this report contain multiple proviral integrations. Nevertheless, the

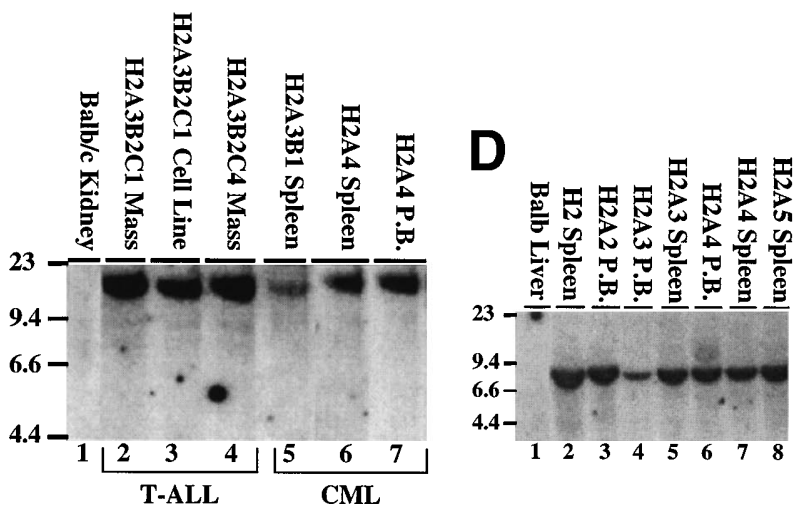

number of proviral integrations is unlikely to explain the difference in disease, because several of the tumors had only a single proviral integration and the phenotype of the disease in these mice was indistinguishable from the disease phenotype in mice harboring multiple proviral integrations.

The murine myeloproliferative disease that we observe in mice receiving P210 transduced bone marrow is very similar to that described by previous investigators. The common features include (1) markedly elevated WBC with granulocyte predominance, (2) splenomegaly, (3) multiple organ involvement, and (4) the presence and expression of the bcr/abl provirus in affected tissues. ${ }^{28,29,31,32}$ One difference in the disease pheno- 
Table 3. Summary of Serial Transplants

\begin{tabular}{lcccccc}
\hline Mouse & Construct & Primary & Secondary & Tertiary & Quaternary & $\begin{array}{c}\text { Identical } \\
\text { Proviral }\end{array}$ \\
\hline H2 & 210 & CML & CML & CML, T-ALL & T-ALL & Yes \\
G4 & $210 / g r b 2$ & CML & T-ALL & ND & Yes \\
G28 & $210 / g r b 2$ & CML & CML, ALL & ND & $*$ \\
G41 & $210 / g r b 2$ & CML & CML & ALL & $*$ \\
G46 & $210 / g r b 2$ & CML & CML & ALL & Yes \\
G57 & $210 / g r b 2$ & CML & CML & ND & Yes \\
SI2 & $210 / g r b 2$ & CML & CML & ND & $*$ \\
\hline
\end{tabular}

Summary of serial transplant experiments. The different constructs are MSCV 210 and MSCV 210/grb2. The diseases are listed under each round of transplant. Where there is more than one disease listed in a column, mice in the cohort developed either one or the other disease, but not both diseases. Proviral integration was determined by digestion of genomic DNA with ECoRI and hybridization with either an IRES or neo probe as described in Materials and Methods. All four tumors analyzed showed an identical proviral integration pattern in secondary, tertiary, and quaternary serial transplant recipients.

Abbreviation: ND, not done.

*Mice died before workup. For these mice, diagnosis was made by morphology. Integrated proviral DNA was present by Xba digestion and PCR (not shown); however, the proviral integration pattern could not be assessed due to degradation.

type in our model is the consistent occurrence of pulmonary hemorrhage, which likely contributes to morbidity and mortality in P210-transplanted mice. One potential explanation is that the high WBC causes stasis in the pulmonary microvasculature, leading to thrombosis and subsequent tissue damage and hemorrhage. This is unlikely to be a complete explanation, because the WBC counts in previous murine CML models were similar to the WBC counts in our model. ${ }^{28,29,31,32}$ A second possibility is platelet dysfunction. Immunohistochemistry showed that at least some megakaryocytes express bcr/abl and abnormally large platelets were observed in the peripheral blood (not shown). Although other investigators have not described pulmonary hemorrhage, evidence of thrombotic complications, including splenic infarcts and apical necrosis of the ears and tail, have been reported. ${ }^{28}$ Pulmonary hemorrhage in mice induced by our protocols may be due to a similar mechanism.

Similar to previous studies, we frequently observe an expansion of macrophages in the liver in association with the myeloproliferative disease. ${ }^{28}$ One difference between the three different retroviral constructs used to induce the myeloproliferative disease was their propensity to cause macrophage proliferation in the liver (Table 2). Twenty percent of mice that received Mig210 bone marrow cells developed the macrophage expansion, whereas $45 \%$ and $90 \%$ of mice receiving MSCV 210/grb2 or MSCV 210, respectively, developed this expansion. Rather than being due to differences in the retroviral vector, this variation may be due to the way in which the bone marrow cells were transduced. In the MSCV 210 and MSCV 210/grb2 experiments, transduction was performed by cocultivation with transfected producer cells, whereas in the Mig 210 experiments, transduction was accomplished by spinoculation. This suggests that the variable macrophage expansion may be explained by enhanced transduction of macrophage progenitors when cocultivation is used, possibly because macrophage precursors adhere more strongly to the adherent producer cells. In spinoculation, this is not a factor, because transduction is performed in the absence of producer cells. In both our model and similar models, ${ }^{28,47}$ the macrophage expansion does not appear to be an essential aspect of the P210 myeloproliferative disease, because the other characteristics of the myeloproliferative disease remain consistent whether or not the macrophage expansion is present. This is further supported by our failure to identify the macrophage expansion in any mice that developed secondary or tertiary tumors after serial transplantation.

Our hybridization studies show that both the myeloproliferative disease and T-cell blast transformation can arise from a single cell containing a single bcr/abl proviral integration. The disease in mice harboring a unique and single proviral integration are clearly monoclonal. Other tumors also appeared to be monoclonal, as suggested by the equal intensity of proviral integration sites on Southern blot. In addition, in all cases of serial passage that we examined, the same proviral integration present in the primary tumor was also present after multiple rounds of serial passage. Together, these results suggest that a single clone is sufficient for murine CML. This is in agreement with previous reports from other groups, in which the myeloproliferative disease and blast transformation was associated with a single clone harboring one proviral integration. ${ }^{28,30-32}$ However, it is not clear if the disease is the result of selection of a single clone arising in the presence of multiply infected cells or if there is only a rare cell that engrafts and subsequently causes the myeloproliferative disease. Previous reports suggested that the latter was the case as a consequence of the transduction conditions. ${ }^{28}$ With the protocols described in this report, it is likely that we are more efficiently transducing bone marrow donor cells than previously described. Consistent with this possibility is our finding of multiple proviral integrations in a majority of the tumors. Further support of our ability to transduce multiple cells is the pattern of GFP expression in tissues of mice receiving MigR1-transduced bone marrow cells. In all tissues, GFP expression is spread over a broad range (Fig 5, column 2), suggesting that expression occurs from multiple clones. In contrast, GFP expression in tissues expressing Mig210 shows a sharp peak (Fig 5, column 2), suggesting that GFP expression arises from one (or a few) clones.

Because the MigR1 and Mig210 retroviral supernatants were normalized for GFP expression before transduction and the donor bone marrow cells were treated identically, the two different viral supernatants should transduce bone marrow cells with equal efficiency. Thus, the differences in the patterns of GFP expression between MigR1 and Mig210 suggest that bcr/abl expression causes the outgrowth of a single (or few) clone(s) with a proliferative advantage. It is unclear if development of the myeloproliferative disease by this clone requires events in addition to bcr/abl expression or if the level of bcr/abl expression determines the ability to cause the myeloproliferative disease. In the latter scenario, there may be multiply bcr/abl-transduced cells that are injected into each recipient mouse but only one or a few of these cells expresses bcr/abl at a level that is sufficient to cause the myeloproliferative disease.

Our serial transplantation studies show that the myeloproliferative disease is transformed into a lymphoma. All of the lymphomas that we have immunophenotyped are immature $\mathrm{T}$ 
cells. These tumors arise in either the thymus, mesenteric lymph nodes, or both. The progression of the myeloproliferative disease to T-cell lymphomas is puzzling, because transduced T cells are a very small proportion of cells in mice with the myeloproliferative disease. In previous descriptions of blast crisis in retroviral murine CML models, transformation occurred in myeloid cells, B cells, and T cells. ${ }^{30,32}$ The propensity for T-cell transformation in our model is unlikely to be due to a bias in expression of the MSCV LTR. As demonstrated by the immunophenotyping results in the MigR1 mice, the Mig retroviral vectors are capable of driving expression in most hematopoietic cell types, including myeloid, B- and T-lymphoid, erythroid, and megakaryocytic cells. A partial explanation for the proclivity for T-cell transformation upon serial passage is that serial transplant itself is biased towards T-cell proliferation. Spangrude et $\mathrm{al}^{48}$ have shown that enriched hematopoietic progenitors lose their ability for multilineage reconstitution after three rounds of serial transplantation and show an increasing bias towards T-cell repopulation. From this perspective, the eventual development of blast crisis in CML patients may not only be due to the accumulation of additional genetic changes, but may also result from the loss of multipotentiality of the bcr/abl-transduced progenitor cell.

Murine CML shares many features with human CML. The murine myeloproliferative disease is characterized by a marked leukocytosis composed primarily of mature neutrophils and myelocytes expressing the bcr/abl fusion protein. Basophils and eosinophils are present in some mice (not shown). Blast forms are rare and lymphadenopathy is minimal. The bone marrow is hypercellular and there is splenomegaly due to a marked increase in maturing myeloid cells. There is also extensive EMH in the liver. Both the murine and human diseases undergo blast transformation, and the blasts express the bcr/abl protein and are derived from the same clone that caused the myeloproliferative disease.

Despite these marked similarities, there are several features of murine CML that are dissimilar to human CML. Most notably, murine CML is a more aggressive myeloproliferative disease than chronic-phase CML, leading to rapid death. This fulminent disease course may be a manifestation of our induction regimen. In patients, the disease arises from a single (or few) cell(s) in a previously immunocompetent individual. In contrast, murine CML is induced by transferring a population of bone marrow progenitor cells expressing bcr/abl to a severely immunocompromised (lethally irradiated) host. The possibility that the host immune status is an important determinant of disease progression is suggested by the results of our single experiment to induce CML in four nonirradiated recipients. At 4 months post-BMT, these mice are healthy, as compared with their lethally irradiated counterparts that die approximately 4 weeks after transfer of P210-transduced bone marrow cells. This result suggests that altering the number of transduced input cells and the conditioning regimen of the recipient mice is likely to alter the disease course. Unlike human CML, in which pulmonary manifestations are rare, murine CML is characterized by pulmonary hemorrhage of uncertain etiology. The hemorrhage may be the consequence of platelet abnormalities, which commonly occur in human CML, ${ }^{1}$ possibly complicated by leukostasis. Blast transformation in our murine model is usually T-lymphoid (rare in human disease), and we have not observed myeloid blast crisis. As discussed, this difference may be a manifestation, in part, of serial transplantation.

In summary, murine CML is not identical to human CML, but does share many of its cardinal features. Murine CML is a biphasic disease that initially presents as a myeloproliferative disease and subsequently undergoes blast transformation. Both the myeloproliferative and blast phases of the disease are associated with expression of the introduced bcr/abl fusion protein. The disease originates in a pluripotential hematopoietic cell that gives rise to a clonal malignancy involving both myeloid and lymphoid lineages. As such, murine CML is a unique and valuable model for investigating (1) the role of $\mathrm{bcr} / \mathrm{abl}$ in transformation, (2) the changes that occur in progenitor cells as the result of bcr/abl expression, and (3) the emergence of blast crisis.

\section{ACKNOWLEDGMENT}

The authors thank the following individuals: Dr J. Jacob and Dr R. Hawley for providing useful reagents; Dr R. Ren for sharing results before publication; and Dr M. Bental-Roof for critical reading of the manuscript. We thank Amgen for providing SCF. We thank the members of the University of Pennsylvania John Morgan (IHGT) and MIT mouse facilities. The flow cytometry studies were performed in the University of Pennsylvania Cancer Center Flow Cytometry and Cell Sorting Shared Resource (supported in part by the Lucille B. Markey Trust and National Cancer Institute Grant No. CA16520).

\section{REFERENCES}

1. Hoffman R, Benz EJ, Shattil SJ, Furie B, Cohen HJ, Silberstein LE: Hematology: Basic Principles and Practice (ed 2). New York, NY, Churchill Livingstone, 1995

2. Clarkson B, Strife A, Perez A, Lambek C, Wisniewski D: Integration of molecular and biological abnormalities in quest for selective treatment of chronic myelogenous leukemia (CML). Leuk Lymphoma 11:81, 1993

3. Nowell PC, Hungerford DA: A minute chromosome in human chronic granulocytic leukemia. Science 132:1197, 1960

4. Groffen J, Stephenson JR, Heisterkamp N, de Klein A, Bartram CR, Grosveld G: Philadelphia chromosomal breakpoints are clustered within a limited region, bcr, on chromosome 22. Cell 36:93, 1984

5. McWhirter JR, Galasso DL, Wang JY: A coiled-coil oligomerization domain of $\mathrm{Bcr}$ is essential for the transforming function of Bcr-Abl oncoproteins. Mol Cell Biol 13:7587, 1993

6. Pendergast AM, Quilliam LA, Cripe LD, Bassing CH, Dai Z, Li N, Batzer A, Rabun KM, Der CJ, Schlessinger J, Gishizky M: BCR-ABL-induced oncogenesis is mediated by direct interaction with the SH2 domain of the GRB-2 adaptor protein. Cell 75:175, 1993

7. Goga A, McLaughlin J, Afar DE, Saffran DC, Witte ON: Alternative signals to RAS for hematopoietic transformation by the BCR-ABL oncogene. Cell 82:981, 1995

8. Maru Y, Witte ON: The BCR gene encodes a novel serine/ threonine kinase activity within a single exon. Cell 67:459, 1991

9. Melo JV: The molecular biology of chronic myeloid leukaemia. Leukemia 10:751, 1996

10. Jackson P, Baltimore D: N-terminal mutations activate the leukemogenic potential of the myristoylated form of c-abl. EMBO J 8:449, 1989

11. Van Etten RA, Jackson PK, Baltimore D, Sanders MC, Matsudaira PT, Janmey PA: The COOH terminus of the c-Abl tyrosine kinase contains distinct F- and G-actin binding domains with bundling activity. J Cell Biol 124:325, 1994 
12. Kipreos ET, Wang JY: Cell cycle-regulated binding of c-Abl tyrosine kinase to DNA. Science 256:382, 1992

13. Konopka JB, Witte ON: Detection of c-abl tyrosine kinase activity in vitro permits direct comparison of normal and altered $a b l$ gene products. Mol Cell Biol 5:3116, 1985

14. Heaney C, Kolibaba K, Bhat A, Oda T, Ohno S, Fanning S, Druker BJ: Direct binding of CRKL to BCR-ABL is not required for BCR-ABL transformation. Blood 89:297, 1997

15. Salgia R, Brunkhorst B, Pisick E, Li JL, Lo SH, Chen LB, Griffin JD: Increased tyrosine phosphorylation of focal adhesion proteins in myeloid cell lines expressing p210BCR/ABL. Oncogene 11:1149, 1995

16. Tauchi T, Boswell HS, Leibowitz D, Broxmeyer HE: Coupling between $\mathrm{p} 210 \mathrm{bcr}-\mathrm{abl}$ and Shc and Grb2 adaptor proteins in hematopoietic cells permits growth factor receptor-independent link to ras activation pathway. J Exp Med 179:167, 1994

17. Yamanashi Y, Baltimore D: Identification of the Abl- and rasGAP-associated $62 \mathrm{kDa}$ protein as a docking protein, Dok. Cell 88:205, 1997

18. Carpino N, Wisniewski D, Strife A, Marshak D, Kobayashi R, Stillman B, Clarkson B: p62(dok): A constitutively tyrosine-phosphorylated, GAP-associated protein in chronic myelogenous leukemia progenitor cells. Cell 88:197, 1997

19. Cortez D, Kadlec L, Pendergast AM: Structural and signaling requirements for BCR-ABL-mediated transformation and inhibition of apoptosis. Mol Cell Biol 15:5531, 1995

20. Oda T, Heaney C, Hagopian JR, Okuda K, Griffin JD, Druker BJ: $\mathrm{Crkl}$ is the major tyrosine-phosphorylated protein in neutrophils from patients with chronic myelogenous leukemia. J Biol Chem 269:22925, 1994

21. Lapidot T, Sirard C, Vormoor J, Murdoch B, Hoang T, CaceresCortes J, Minden M, Paterson B, Caligiuri MA, Dick JE: A cell initiating human acute myeloid leukaemia after transplantation into SCID mice. Nature 367:645, 1994

22. Lewis ID, McDiarmid LA, Samels LM, To LB, Hughes TP: Establishment of a reproducible model of chronic-phase chronic myeloid leukemia in NOD/SCID mice using blood-derived mononuclear or CD34 ${ }^{+}$cells. Blood 91:630, 1998

23. Hariharan IK, Harris AW, Crawford M, Abud H, Webb E, Cory S, Adams JM: A $b c r-\mathrm{v}-a b l$ oncogene induces lymphomas in transgenic mice. Mol Cell Biol 9:2798, 1989

24. Heisterkamp N, Jenster G, ten Hoeve J, Zovich D, Pattengale PK, Groffen J: Acute leukemia in bcr/abl transgenic mice. Nature 344:251, 1990

25. Honda H, Fujii T, Takatoku M, Mano H, Witte ON, Yazaki Y, Hirai $\mathrm{H}$ : Expression of $\mathrm{p} 210 \mathrm{bcr} / \mathrm{abl}$ by metallothionein promoter induced T-cell leukemia in transgenic mice. Blood 85:2853, 1995

26. Honda H, Oda H, Suzuki T, Takahashi T, Witte ON, Ozawa K, Ishikawa T, Yazaki Y, Hirai H: Development of acute lymphoblastic leukemia and myeloproliferative disorder in transgenic mice expressing p210(bcr/abl): A novel transgenic model for human $\mathrm{Ph} 1$-positive leukemias. Blood 91:2067, 1998

27. Daley GQ: Animal models of BCR/ABL-induced leukemias. Leuk Lymphoma 11:57, 1993 (suppl 1)

28. Daley GQ, Van Etten RA, Baltimore D: Induction of chronic myelogenous leukemia in mice by the P210bcr/abl gene of the Philadelphia chromosome. Science 247:824, 1990

29. Kelliher MA, McLaughlin J, Witte ON, Rosenberg N: Induction of a chronic myelogenous leukemia-like syndrome in mice with $\mathrm{v}$-abl and BCR/ABL. Proc Natl Acad Sci USA 87:6649, 1990

30. Daley GQ, Van Etten RA, Baltimore D: Blast crisis in a murine model of chronic myelogenous leukemia. Proc Natl Acad Sci USA 88:11335, 1991
31. Elefanty AG, Cory S: Hematologic disease induced in BALB/c mice by a bcr-abl retrovirus is influenced by the infection conditions. Mol Cell Biol 12:1755, 1992

32. Gishizky ML, Johnson-White J, Witte ON: Efficient transplantation of BCR-ABL-induced chronic myelogenous leukemia-like syndrome in mice. Proc Natl Acad Sci USA 90:3755, 1993

33. Hawley RG, Lieu FH, Fong AZ, Hawley TS: Versatile retroviral vectors for potential use in gene therapy. Gene Ther 1:136, 1994

34. Egan SE, Giddings BW, Brooks MW, Buday L, Sizeland AM, Weinberg RA: Association of Sos Ras exchange protein with Grb2 is implicated in tyrosine kinase signal transduction and transformation. Nature 363:45, 1993

35. Pear WS, Aster JC, Scott ML, Hasserjian RP, Soffer B, Sklar J, Baltimore D: Exclusive development of $\mathrm{T}$ cell neoplasms in mice transplanted with bone marrow expressing activated Notch alleles. J Exp Med 183:2283, 1996

36. Kotani H, Newton PBr, Zhang S, Chiang YL, Otto E, Weaver L, Blaese RM, Anderson WF, McGarrity GJ: Improved methods of retroviral vector transduction and production for gene therapy. Hum Gene Ther 5:19, 1994

37. Pear WS, Cepko C: Transduction of genes using retrovirus vectors, in Ausubel FM, Brent R, Kingston RE, Moore DD, Seidman JG, Smith JA, Struhl K (eds): Current Protocols in Molecular Biology, Supplement 36. New York, NY, Wiley, 1996, p 9.9.1

38. Coligan JE, Kruisbeek AM, Margulies DH, Shevach EM, Strober W: Current Protocols in Immunology. New York, NY, Wiley, 1992

39. Spangrude GJ: Biological and clinical aspects of hematopoietic stem cells. Annu Rev Med 45:93, 1994

40. Pear WS, Nolan GP, Scott ML, Baltimore D: Production of high-titer helper-free retroviruses by transient transfection. Proc Natl Acad Sci USA 90:8392, 1993

41. Bodine DM, Orlic D, Birkett NC, Seidel NE, Zsebo KM: Stem cell factor increases colony-forming unit-spleen number in vitro in synergy with interleukin-6, and in vivo in S1/Sld mice as a single factor. Blood 79:913, 1992

42. Pawliuk R, Kay R, Lansdorp P, Humphries RK: Selection of retrovirally transduced hematopoietic cells using $\mathrm{CD} 24$ as a marker of gene transfer. Blood 84:2868, 1994

43. Schott B, Iraj ES, Roninson IB: Effects of infection rate and selection pressure on gene expression from an internal promoter of a double gene retroviral vector. Somat Cell Mol Genet 22:291, 1996

44. Hestdal K, Ruscetti FW, Ihle JN, Jacobsen SE, Dubois CM, Kopp WC, Longo DL, Keller JR: Characterization and regulation of RB6-8C5 antigen expression on murine bone marrow cells. J Immunol 147:22, 1991

45. Scott ML, Van Etten RA, Daley GQ, Baltimore D: v-abl causes hematopoietic disease distinct from that caused by bcr-abl. Proc Natl Acad Sci USA 88:6506, 1991

46. Hawley RG, Fong AZ, Ngan BY, de Lanux VM, Clark SC, Hawley TS: Progenitor cell hyperplasia with rare development of myeloid leukemia in interleukin 11 bone marrow chimeras. J Exp Med 178:1175, 1993

47. Zhang X, Ren R: Bcr-Abl efficiently induces a myeloproliferative disease and production of excess interleukin-3 and granulocytemacrophage colony-stimulating factor in mice: A novel model for chronic myelogenous leukemia. Blood 92:3829, 1998

48. Spangrude GJ, Brooks DM, Tumas DB: Long-term repopulation of irradiated mice with limiting numbers of purified hematopoietic stem cells: In vivo expansion of stem cell phenotype but not function. Blood $85: 1006,1995$ 